\title{
PENGARUH PROMOSI DAN PELAYANAN TERHADAP TINGKAT \\ KUNJUNGAN TAMU PADA \\ HOTEL INNA DHARMA DELI \\ MEDAN
}

\author{
Sumiati, Edi Winata, Wardayani \\ Alumni Sekolah Tinggi Ilmu Manajemen Sukma \\ Program studi Manajemen, Sekolah Tinggi Ilmu Manajemen \\ Ediwinatarivail1916@gmail.com, Wardayani302@gmail.com
}

\begin{abstract}
The study aims to find out whether there is any effect of Promotion and Serviceon guest visit rate on Inna Dharma Deli Medan. The population of this study is consumerMei 2017 as many as 80 people. The sampling method used was simple ramdom sampling as many as 80 respondents. The data of the study was analyzed using Simple Linier Regression test with testing hypothesis by t-test and coefficient of determination $\left(R^{2}\right)$ while data processing used SPSS 20 program. Previously it has got validity and reability test for research instrument. Study result shows that based on partial t-test promotion and service has positive and significantlyinfluence toguest visit rate on Inna Dharma Deli Medan. While the ability of the Promotion and Service to explain the level of guest visit rate was as much as 60,7\% while the rest was explained by other variables which are excluded in this study model.
\end{abstract}

Keywords: Promotion, Serviceand guest visit rate

\section{PENDAHULUAN}

Hotel adalah suatu akomodasi yang menyediakan pelayanan jasa penginapan, penyedia makanan dan minuman berikut dengan harga yang bervariasi yang disesuaikan dengan masing-masing makanan dan minuman, serta jasa fasilitas lainnya dimana semua pelayanan itu diperuntukkan bagi masyarakat umum, baik mereka yang bermalam di hotel tersebut ataupun mereka yang hanya menggunakan fasilitas tertentu yang dimiliki hotel itu yang berujung kepada kepuasan Konsumen. Adapun sifat konsumen yang lebih selektif dalam menentukan apa yang menjadi pilihannya membuat perusahaan berkompetisi untuk memberikan sesuatu yang sesuai dengan kebutuhan dan keinginan calon konsumennya. Seperti yang kita ketahui bahwa tawaran produk dan jasa sudah sangat beragam dewasa ini, terutama di bagian jasa pelayanan seperti hotel. Pilihan yang beragam membuat konsumen bebas menentukan pilihannya terhadap tempat jasa pelayanan seperti hotel yang dapat membuat konsumen merasa puas atas apa yang dia pilih dalam jasa pelayanan seperti hotel tersebut. Dari sudut pandang pengunjung, promosi dan pelayanan sering dijadikan indikator dalam menentukan atau memilih sesuatu. Promosi adalah merupakan ajakan atau bujukan yang diberikan oleh penyedia jasa pelayanan yang baik dalam mempengaruhi pengunjung. Pelayanan prima adalah jasa yang diberikan kepada konsumen. Kunjungan tamu adalah hasrat atau keinginan tamu untuk berkunjung kesuatu tempat tersebut karena promosi dan pelayanan yang baik. Promosi yang baik dan pelayanan prima yang disajikan atau ditawarkan berdampak pada tingkat kunjungan tamu.

Areks et al (2015) dalam penelitiannya menyimpulkan bahwa Hasil analisis menunjukkan bahwa bauran promosi secara simultan berpengaruh terhadap tingkat kunjungan wisatawan, sedangkan secara parsial hanya advertising dan word of mouth marketing yang berpengaruh nyata terhadap tingkat kunjungan wisatawan. Setiawan 
(2014) dalam penelitiannya menyimpulkan bahwa: (1) Promosi berpengaruh signifikan terhadap kepuasan pelanggan, maka secara parsial variabel Promosi (X1) berpengaruh signifikan terhadap Kepuasan Pelanggan (Y) dengan asumsi variabel bebas lainnya konstan.; (2) Kualitas pelayanan berpengaruh signifikan terhadap loyalitas konsumen, maka secara parsial variabel Kualitas Layanan (X2) berpengaruh signifikan terhadap Kepuasan Pelanggan (Y) dengan asumsi variabel bebas lainnya konstan. (3) Promosi dan kualitas pelayanan secara bersama-sama berpengaruh terhadap kepuasan pelanggan aka secara parsial variabel Promosi dan variabel Kualitas Pelayanan (X2) secara serentak berpengaruh signifikan terhadap Kepuasan Pelanggan (Y) dengan asumsi variabel bebas lainnya konstan. Dengan demikian hipotesis yang menyebutkan bahwa variabel Promosi dan variabel Kualitas Pelayanan secara serentak berpengaruh terhadap Kepuasan Pelanggan terbukti atau diterima.

\section{Perumusan Masalah}

Perumusan masalah penelitian ini yaitu apakah ada pengaruh promosi dan pelayanan terhadap tingkat kunjungan tamu pada Hotel Inna Dharma Deli Medan secara parsial dan simultan.

\section{Batasan Masalah}

Penulis membatasi penelitian pada minggu pertama dan kedua bulan Mei 2017, khususnya pada pengunjung individu atau Free Individual Travel (FIT) yang menginap lebih dari satu malam pada Inna Dharma Deli Medan.

\section{Tujuan Penelitian}

Adapun tujuan dari penelitian ini adalah untuk mengetahui pengaruh promosi dan pelayanan terhadap tingkat kunjungan tamu secara parsial dan simultan di Inna Dharma Deli Medan.

\section{METODE PENELITIAN}

\section{Tempat dan Waktu Penelitian}

Penelitian ini dilakukan diInna Dharma Deli Medan yang beralamat di Jalan Balai Kota No. 2, Kota Medan. Penelitian dilaksanakan pada bulan Maret 2017 sampai Mei 2017.

\section{Jenis dan Sumber Data}

Jenis Data

Data yang digunakan dalam penelitian ini adalah data primer dan data skunder.

1 Data Primer adalah sumber data yang secara langsung memberikan data kepada pengumpul data (Sugiyono, 2012:25). Data primer berupa catatan hasil wawancara yang diperoleh melalui wawancara yang penulis lakukan. Selain itu, mengumpulkan data dalam bentuk catatan tentang situasi dan kejadian di perpustakaan.

2 Data Sekunder merupakan sumber data yang tidak memberikan informasi secara langsung kepada pengumpul data. Sumber data sekunder ini pengolahan lebih lanjut dari data primer yang disajikan dalam bentuk lain atau orang lain (Sugiyono,2012:25). Data digunakan untuk mendukung informasi dari data skunder.

Sumber Data

Sumber data yang digunakan yaitu:

1. Data Internal yaitu data yang didapat dari tempat penelitian dengan cara membagikan dan mengumpulkan kembali angket kepada pengunjung Inna Dharma Deli Medan. 
Dimana data tersebut merupakan data mentah dan harus diolah sebelum dituangkan ke dalam skripsi.

2. Data Eksternal adalah data yang didapat dari luar tempat penelitian seperti internet dan perpustakaan.

\section{Metode Pengumpulan Data}

Untuk mendapatkan bahan yang diperlukan dalam menyelesaikan skripsi ini penulis melakukan 2 penelitian yaitu:

1 Penelitian Kepustakaan.

2 Penelitian Lapangan, pengumpulan data yang digunakan dalam penelitian ini sebagai berikut:

a. Studi Dokumentasi: pengumpulan data yang dilakukan dengan mencari informasi berdasarkan dokumen-dokumen perusahaan yang berkaitan dengan penelitian.

b. Kuesioner: metode pengumpulan data dengan membuat daftar pernyataan dalam bentuk angket yang ditujukan kepada responden yang dijadikan sampel.

c. Observasi: data melalui pengamatan secara langsung di Inna Dharma Deli Medan.

\section{Definisi Operasional}

Definisi operasional adalah merupakan petunjuk pelaksanaan bagaimana cara mengukur suatu variabel sebagai berikut:

1. Variabel bebas adalah variabel yang mempengaruhi variabel terikat, yang terdiri dari promosi $\left(\mathrm{X}_{1}\right)$ dan pelayanan $\left(\mathrm{X}_{2}\right)$.

2. Variabel terikat adalah variabel yang dipengaruhi variabel bebas, yaitu kunjungan tamu (Y).

Tabel 3.2. Operasionalisasi Variabel Penelitian

\begin{tabular}{|c|c|c|c|c|}
\hline N & Variabel & Definisi & Indikator & $\begin{array}{l}\text { Skala } \\
\text { Ukur }\end{array}$ \\
\hline 1 . & $\begin{array}{l}\text { Promosi } \\
\left(\mathrm{X}_{1}\right)\end{array}$ & $\begin{array}{lr}\text { Sejenis } & \text { komunikasi } \\
\text { yang } & \text { memberi } \\
\text { penjelasan } & \text { yang } \\
\text { meyakinkan } & \text { calon } \\
\text { konsumen } & \text { tentang } \\
\text { barang dan jasa. }\end{array}$ & $\begin{array}{l}\text { 1. Personal Selling (penjualan } \\
\text { personal) } \\
\text { 2. SalesPromotion(promosipen } \\
\text { jualan) } \\
\text { 3. Public Relation (Humas) } \\
\text { 4. Advertising (periklanan) }\end{array}$ & Likert \\
\hline 2. & $\begin{array}{l}\text { Pelayana } \\
\text { n } \\
\left(\mathrm{X}_{2}\right)\end{array}$ & $\begin{array}{l}\text { Suatu kegiatan atau } \\
\text { urutan kegiatan yang } \\
\text { terjadi dalam } \\
\text { interaksi langsung } \\
\text { seseorang dengan } \\
\text { orang lain atau mesin } \\
\text { secara fisik, dan } \\
\text { menyediakan } \\
\text { kepuasan pelanggan. }\end{array}$ & $\begin{array}{ll}\text { 1. } & \text { Tangible (tak berwujud) } \\
\text { 2. } & \text { Inseparabilit } \quad y(\text { tak } \\
\text { terpisahkan) } \\
\text { 3. } & \text { Variability (bervariasi) } \\
\text { 4. } & \text { Perishability (Mudah } \\
& \text { Musnah) }\end{array}$ & Likert \\
\hline & $\begin{array}{l}\text { Kunjung } \\
\text { an Tamu } \\
\text { /Kepuas } \\
\text { an } \\
\text { (Y) }\end{array}$ & $\begin{array}{l}\text { Terdiri dari beberapa } \\
\text { orang dengan } \\
\text { bermacam-macam } \\
\text { motivasi kunjungan } \\
\text { termasuk didalamnya } \\
\text { adalah wisatawan, } \\
\text { sehingga tidak semua } \\
\text { pengunjung termasuk }\end{array}$ & $\begin{array}{ll}\text { 1. } & \text { Attention (menaruh } \\
\text { perhatian) } \\
\text { 2. Interest (ketertarikan) } \\
\text { 3. Desire (keinginan) } \\
\text { 4. } \text { Action (tindakan) }\end{array}$ & Likert \\
\hline
\end{tabular}


\begin{tabular}{|l|l|l|l|}
\hline & wisatawan. & & \\
\hline
\end{tabular}

Sumber Data: Manap (2016), Jaiz (2012), Barata (2012) Tjiptono (2013), Sulastiyono (2013), Kemala (2013)

\section{Uji Validitas dan Reliabilitas}

Menurut Sugiyono (2012:110) "uji validitas adalah suatau langkah pengujian yang dilakukan terhadap isi dari suatu instrumen, dengan tujuan untuk mengukur ketepatan instrumen yang digunakan dalam suatu penelitian". Dikatakan valid jika nilai $t_{\text {hitung }} \geq t_{\text {tabel }}$ dan dikatakan tidak valid jika nilai $t_{\text {hitung }}<t_{\text {tabel. }}$

Menurut Sugiyono (2012:111) "uji reliabilitas adalah proses pengukuran terhadap ketepatan (konsisten) dari suatu instrumen". Dikatakan reliabel jika nilai crombach alfa $>$ 0.6 dan dikatakan tidak reliable jika nilai crombach alfa $<0.6$

\section{Metode Analisis Data}

Analisis data dalam penelitian ini menggunakan analisis regresi linier sederhana dengan model persamaan: $Y=a+b_{1} X_{1}+b_{2} X_{2}+e$

Dimana :

$$
\begin{array}{rll} 
& \text { Y } & =\text { Pengunjung } \\
& \mathrm{X}_{1} & =\text { Promosi } \\
\mathrm{X}_{2} & =\text { Pelayanan } \\
\mathrm{a} & =\text { Konstanta } \\
\mathrm{b}_{1} & & =\text { Koefisien regresi variabel promosi } \\
\mathrm{b}_{2} & & =\text { Koefisien regresi variable pelayanan } \\
\mathrm{e} & & =\text { error of term (variabel yang tidak diteliti) }
\end{array}
$$

\section{Kerangka Berfikir}

promosi adalah sejenis komunikasi yang memberi penjelasan yang meyakinkan calon konsumen tentang barang dan jasa. Pelayanan adalah suatu kegiatan atau urutan kegiatan yang terjadi dalam interaksi langsung seseorang dengan orang lain atau mesin secara fisik, dan menyediakan kepuasan pelanggan. Pengunjung adalah terdiri dari beberapa orang dengan bermacam-macam motivasi kunjungan termasuk didalamnya adalah wisatawan, sehingga tidak semua pengunjung termasuk wisatawan.

\section{Hipotesis}

Berdasarkan pengertian diatas, maka hipotesis penelitian ini adalah "ada pengaruh promosi dan pelayanan terhadap tingkat kunjungan tamu pada Inna Dharma Deli Medan" secara parsial dan simultan.

\section{Pengujian Hipotesis}

\section{a. Koefisien Determinasi $\left(\mathrm{R}^{2}\right)$}

Koefisien determinasi $\left(\mathrm{R}^{2}\right)$ pada intinya menukur seberapa besar kemampuan model dalam menerangkan variabel terikat. Semakin besar nilai koefisien determinasi (mendekati satu), maka dapat dikatakan bahwa pengaruh variabel bebas $\left(\mathrm{X}_{1}\right.$ dan $\left.\mathrm{X}_{2}\right)$ adalah besar terhadap variabel terikat(Y).

b. Uji Simultan (Uji F)

Untuk menguji hipotesisi penelitian ini digunakan uji simultan (uji F), uji ini dilakukan untuk melihat pengaruh promosi dan pelayanan secara simultan terhadap tingkat kunjungan tamu, pengujian dilakukan pada tingkat kepercayaan $90 \%$ atau tingkat kesalahan $\alpha=0,10(10 \%)$, dengan kriteria:

1. Jika $\mathrm{F}_{\text {hitung }} \leq \mathrm{F}_{\text {tabel, }}$, maka $\mathrm{H}_{0}$ diterima, $\mathrm{H}_{1}$ ditolak, artinya secara simultan penelitian ini tidak berpengaruh.

2. Jika $\mathrm{F}_{\text {hitung }}>\mathrm{F}_{\text {tabel }}$, maka $\mathrm{H}_{0}$ ditolak, $\mathrm{H}_{1}$ diterima, artinya secara simultan penelitian ini berpengaruh. 


\section{Uji Parsial (uji t)}

Uji parsial (Uji t) bertujuan untuk melihat pengaruh promosi dan pelayanan terhadap tingkat kunjungan, dengan kriteria :

1. Jika $t_{\text {hitung }} \leq t_{\text {tabel }}$ maka $\mathrm{H}_{0}$ diterima, $\mathrm{H}_{1}$ ditolak, artinya secara parsial penelitian ini tidak berpengaruh.

2. Jika $t_{\text {hitung }}>t_{\text {tabel }}$ maka $H_{0}$ ditolak, $H_{1}$ diterima, artinya secara parsial penelitian ini berpengaruh.

\section{HASIL PENELITIAN DAN PEMBAHASAN}

\section{Hasil Penelitian}

\section{Uji validitas}

Tabel 2. Validitas Instrumen Variabel Promosi $\left(\mathrm{X}_{1}\right)$

\begin{tabular}{|l|l|l|l|}
\hline Instrumen & \multicolumn{2}{|l|}{ Nilai Validitas } & Kesimpulan \\
\cline { 2 - 2 } & rhitung & Rtabel & \\
\hline Promosi 1 & 0.114 & & Tidak Valid \\
\hline Promosi 2 & 0.198 & & Tidak Valid \\
\hline Promosi 3 & 0.178 & & Tidak Valid \\
\hline Promosi 4 & 0.550 & & Valid \\
\hline Promosi 5 & 0.462 & \\
& & Valid \\
& Promosi 6 & 0.562 & Valid \\
\hline Promosi 7 & 0.288 & Valid \\
\hline Promosi 8 & 0.380 & \multirow{n}{*}{0.221} & Valid \\
\hline Promosi 9 & 0.301 & & Valid \\
\hline Promosi 10 & 0.235 & & Valid \\
\hline
\end{tabular}

Dari tabel 2. terlihat bahwa hasil pengujian masing-masing instrument variabel promosi $\left(\mathrm{X}_{1}\right)$ memiliki nilai r-hitung $>0.221$, dengan demikian dapat disimpulkan bahwa 7 instrument yang valid dan 3 instrument yang tidak valid.

Tabel 3. Validitas Instrumen Variabel Pelayanan $\left(\mathrm{X}_{2}\right)$

\begin{tabular}{|l|l|l|l|}
\hline \multirow{2}{*}{ Instrumen } & \multicolumn{2}{|l|}{ Nilai Validitas } & Kesimpulan \\
\cline { 2 - 2 } & rhitung & Rtabel & \\
\hline Pelayanan 1 & 0.285 & & Valid \\
\hline Pelayanan 2 & 0.455 & & Valid \\
\hline Pelayanan 3 & 0.489 & & Valid \\
\hline Pelayanan 4 & 0.527 & & Valid \\
\hline Pelayanan 5 & 0.502 & \multirow{n}{*}{0.221} & Valid \\
\hline Pelayanan 6 & 0.467 & Valid \\
\hline Pelayanan 7 & 0.374 & & Valid \\
\hline Pelayanan 8 & 0.331 & & Valid \\
\hline Pelayanan 9 & 0.333 & & Valid \\
\hline Pelayanan 10 & 0.279 & & Valid \\
\hline
\end{tabular}

Dari tabel 3. terlihat bahwa hasil pengujian masing-masing instrument variabel pelayanan $\left(\mathrm{X}_{2}\right)$ memiliki nilai r-hitung $>0.221$, dengan demikian dapat disimpulkan bahwa secara keseluruhan instrument pernyataan dari variabel pelayanan yang digunakan valid. 
Tabel 4. Validitas Instrumen Variabel Kunjungan (Y)

\begin{tabular}{|l|l|l|l|}
\hline \multirow{2}{*}{ Instrumen } & \multicolumn{2}{|l|}{ Nilai Validitas } & Kesimpulan \\
\cline { 2 - 2 } & rhitung & Rtabel & \\
\hline Kunjungan 1 & 0.503 & & Valid \\
\hline Kunjungan 2 & 0.210 & & Valid \\
\hline Kunjungan 3 & 0.380 & & Valid \\
\hline Kunjungan 4 & 0.385 & \\
\hline Kunjungan 5 & 0.430 & Valid \\
\hline Kunjungan 6 & 0.372 & Valid \\
\hline Kunjungan 7 & 0.430 & & Valid \\
\hline Kunjungan 8 & 0.237 & & Valid \\
\hline Kunjungan 9 & 0.442 & Valid \\
\hline Kunjungan 10 & 0.332 & & Valid \\
& Valid \\
\hline
\end{tabular}

Dari tabel 4. terlihat bahwa hasil pengujian masing-masing instrument variabel kunjungan tamu (Y) memiliki nilai r-hitung $>0.221$, dengan demikian dapat disimpulkan bahwa secara keseluruhan instrument pernyataan dari variabel kunjungan tamu yang digunakan valid.

\section{Uji reliabilitas}

Tabel 5. Hasil Reliabilitas Instrumen Penelitian

\begin{tabular}{|l|l|l|l|}
\hline No & Variabel & Nilai Cronbach's Alpha & Kesimpulan \\
\hline 1 & Promosi & 0.664 & Reliabel \\
\hline 2 & Pelayanan & 0.744 & Reliabel \\
\hline 3 & Kunjungan Tamu & 0.710 & Reliabel \\
\hline
\end{tabular}

Hasil uji reliabilitas menunjukkan bahwa nilai Cronbach alfaseluruh variabel lebih besar dari 0.6, maka dapat disimpulkan bahwa angket penelitian ini dikatakan reliabel.

\section{Hasil Uji Regresi Linear Berganda}

Tabel 6. Hasil regresi Linear Berganda

\begin{tabular}{|c|c|c|c|c|c|c|}
\hline \multicolumn{7}{|c|}{ Coefficients $^{\mathrm{a}}$} \\
\hline \multirow[t]{2}{*}{ Model } & & \multicolumn{2}{|c|}{$\begin{array}{l}\text { Unstandardized } \\
\text { Coefficients }\end{array}$} & \multirow{2}{*}{\begin{tabular}{|l}
$\begin{array}{l}\text { Standardized } \\
\text { Coefficients }\end{array}$ \\
Beta
\end{tabular}} & \multirow[t]{2}{*}{$\mathrm{T}$} & \multirow[t]{2}{*}{ Sig. } \\
\hline & & B & Std. Error & & & \\
\hline \multirow[t]{3}{*}{1} & (Constant) & 13.206 & 4.707 & & 2.806 & .006 \\
\hline & Promosi & .042 & .177 & .027 & .236 & .814 \\
\hline & Pelayanan & .633 & .120 & .609 & 5.262 & .000 \\
\hline
\end{tabular}

Berdasarkan hasil pengujian diatas, maka diperoleh persamaan regresi linier berganda sebagai berikut:

$\mathrm{Y}=13.206+0.042 \mathrm{X}_{1}+0.633 \mathrm{X}_{2}$

Pada model regresi linier berganda diperoleh nilai konstanta tingkat kunjungan tamu sebesar 13.206 artinya jika nilai variabel bebas $\left(X_{1}\right.$ dan $\left.X_{2}\right)$ nilainya 0 , maka variabel terikat $(\mathrm{Y})$ nilainya sebesar 13.206 . Koefisien regresi masing-masing variabel bebas bernilai positif, artinya tingkat kunjungan tamu pada Inna Dharma Deli Medan dapat dipengaruhi oleh promosi dan pelayanan. 


\section{Pengujian Hipotesis}

a. Koefisien Determinasi $\left(\mathrm{R}^{2}\right)$

Tabel 7. Hasil Uji Koefisien Determinasi $\left(\mathrm{R}^{2}\right)$

\begin{tabular}{|l|l|l|l|l|}
\hline Model Summary & \multicolumn{3}{l|}{} \\
\hline Model & R & R Square & Adjusted R Square & Std. Error of the Estimate \\
\hline 1 & $.627^{\mathrm{a}}$ & .393 & .377 & 3.540 \\
\hline
\end{tabular}

a.Predictors; (Constant), promosi, pelayanan_tingkat kunjungan

Nilai koefisien determinasi yang diperoleh sebesar 0.393 atau 39.3\%, menunjukkan bahwa variabel promosi dan pelayanan mampu menjelaskan variasi yang terjadi pada tingkat kunjungan tamu pada Inna Dharma Deli Medan, sedangkan sisanya $60.7 \%$ dijelaskan pada variabel lain yang tidak yang tidak diteliti dalam penelitian ini seperti keramahtamahan pegawai hotel yang membuat tamu merasa seperti dirumah sendiri.

\section{Uji Simultan (uji F)}

Uji simultan (F), uji ini dilakukan untuk melihat pengaruh promosi dan pelayanan secara simultan terhadap tingkat kunjungan tamu, pengujian dilakukan pada tingkat kepercayaan $90 \%$ atau tingkat kesalahan $\alpha=0.10(10 \%)$, dengan kriteria:

1. Jika $\mathrm{F}_{\text {hitung }} \leq \mathrm{F}_{\text {tabel}}$, maka $\mathrm{H}_{0}$ diterima $\mathrm{H}_{1}$ ditolak, artinya secara simultan penelitian ini tidak berpengaruh

2. Jika $\mathrm{F}_{\text {hitung }}>\mathrm{F}_{\text {tabel, }}$, maka $\mathrm{H}_{0}$ ditolak, $\mathrm{H}_{1}$ diterima, artinya secara simultan penelitian ini berpengaruh.

Tabel 8. Hasil Uji Simultan (Uji F)

\begin{tabular}{|l|l|l|l|l|l|l|}
\hline ANOVA $^{\text {a }}$ & \multicolumn{7}{l|}{} \\
\hline Model & & Sum of Squares & Df & Mean Square & F & Sig. \\
\hline \multirow{1}{*}{1} & Regression & 624.216 & 2 & 312.108 & 24.910 & $.000^{\mathrm{b}}$ \\
\cline { 2 - 8 } & Residual & 964.771 & 77 & 12.529 & & \\
\cline { 2 - 7 } & Total & 1588.987 & 79 & & & \\
\hline
\end{tabular}

Berdasarkan tabel tersebut dapat dilihat bahwa nilai $\mathrm{F}_{\text {hitung }}$ yaitu $24.910>$ dari nilai $\mathrm{F}_{\text {tabel }}$ yaitu 2.72 dan nilai signifikan $0.000<$ dari nilai alpha 0.10 . Maka keputusan yang diambil $\mathrm{H}_{0}$ ditolak $\mathrm{H}_{1}$ diterima. Dengan diterimanya $\mathrm{H}_{1}$ menunjukkan bahwa variabel bebas yang terdiri dari promosi $\left(\mathrm{X}_{1}\right)$ dan pelayanan $\left(\mathrm{X}_{2}\right)$ mampu menjelaskan keragaman variabel terikat $(\mathrm{Y})$, dengan demikian variabel promosi dan pelayanan secara simultan berpengaruh positif dan signifikan terhadap tingkat kunjungan tamu pada Inna Dharma Deli Medan.

\section{Uji Parsial (uji t)}

Tabel 9. Hasil uji parsial

\begin{tabular}{|c|c|c|c|c|c|c|}
\hline \multicolumn{7}{|c|}{ Coefficients ${ }^{\mathrm{a}}$} \\
\hline \multirow[t]{3}{*}{ Model } & & \multirow{2}{*}{\multicolumn{2}{|c|}{$\begin{array}{l}\text { Unstandardized } \\
\text { Coefficients }\end{array}$}} & \multirow{3}{*}{\begin{tabular}{|l|} 
Standardized \\
Coefficients \\
Beta \\
\end{tabular}} & \multirow[t]{3}{*}{$T$} & \multirow[t]{3}{*}{ Sig. } \\
\hline & & & & & & \\
\hline & & $\mathrm{B}$ & Std. Error & & & \\
\hline \multirow[t]{3}{*}{1} & (Constant) & 13.206 & 4.707 & & 2.806 & .006 \\
\hline & Promosi & .042 & .177 & .027 & .236 & .814 \\
\hline & Pelayanan & 633 & .120 & .609 & 5.262 & .000 \\
\hline
\end{tabular}

Berdasarkan tabel tersebut dapat dilihat bahwa:

1. Nilai $t_{\text {hitung }}$ untuk variabel promosi $0.236>t_{\text {tabel }} 1.991$ dan nilai signifikan $0.814>$ dari alpha 0.10 , maka $\mathrm{H}_{0}$ ditolak dan $\mathrm{H}_{1}$ diterima, dengan demikian secara parsial variabel promosi berpengaruh terhadap tingkat kunjungan tamu; 
2. Nilai $\mathrm{t}_{\text {hitung }}$ untuk variabel pelayanan $5.262>\mathrm{t}_{\text {tabel }} 1.991$ dan nilai signifikan $0.0000>$ dari nilai alpha 0.10 , maka $\mathrm{H}_{0}$ ditolak dan $\mathrm{H}_{1}$ diterima, dengan demikian secara parsial variabel pelayanan berpengaruh positif dan signifikan terhadap tingkat kunjungan tamu.

\section{Pembahasan}

Hasil pengujian hipotesis pertama menunjukkan bahwa variabel promosi dan pelayanan mampu menjelaskan variasi yang terjadi pada tingkat kunjungan tamu di Inna Dharma Deli Medan, ini dibuktikan dengan nilai koefisien determinasi $\left(\mathrm{R}^{2}\right)$ yang diperoleh sebesar 0.393 atau $39.3 \%$, , sedangkan sisanya sebesar $60.7 \%$ dijelaskan pada variabel lain yang tidak yang tidak diteliti dalam penelitian ini.

Hasil pengujian hipotesis kedua menunjukkan bahwa variabel promosi dan pelayanan secara simultan berpengaruh positif dan signifikan terhadap tingkat kunjungan tamu pada Inna Dharma Deli Medan, ini dibuktikan dengan nilai $\mathrm{F}_{\text {hitung }}$ yaitu $24.910>$ dari nilai $\mathrm{F}_{\text {tabel }} 2.72$ yaitu dan nilai signifikan $0.000<$ dari nilai alpha 0.10 . Hasil penelitian ini sesuai dengan hasil penelitian yang dilakukan oleh, Arekset al(2015) dalam penelitiannya menyimpulkan bahwa menunjukkan bahwa bauran promosi secara simultan berpengaruh terhadap tingkat kunjungan wisatawan, sedangkan secara parsial hanya advertising dan word of mouth marketing yang berpengaruh nyata terhadap tingkat kunjungan wisatawan.

Hasil pengujian hipotesis ketiga menunjukkan bahwa secara parsial pelayanan berpengaruh pada tingkat kunjungan tamu . Hasil penelitian ini sesuai dengan penelitian yang dilakukan oleh Setiawan (2014) dalam penelitiannya menyimpulkan bahwa: (1) Promosi berpengaruh signifikan terhadap kepuasan pelanggan, maka secara parsial variabel Promosi (X1) berpengaruh signifikan terhadap Kepuasan Pelanggan (Y) dengan asumsi variabel bebas lainnya konstan.; (2) Kualitas pelayanan berpengaruh signifikan terhadap loyalitas konsumen, maka secara parsial variabel Kualitas Layanan (X2) berpengaruh signifikan terhadap Kepuasan Pelanggan (Y) dengan asumsi variabel bebas lainnya konstan. (3) Promosi dan kualitas pelayanan secara bersama-sama berpengaruh terhadap kepuasan pelanggan aka secara parsial variabel Promosi dan variabel Kualitas Pelayanan (X2) secara serentak berpengaruh signifikan terhadap Kepuasan Pelanggan (Y) dengan asumsi variabel bebas lainnya konstan. Dengan demikian hipotesis yang menyebutkan bahwa variabel Promosi dan variabel Kualitas Pelayanan secara serentak berpengaruh terhadap Kepuasan Pelanggan terbukti atau di

Data diperoleh berdasarkan pengamatan langsung dan wawancara yang dilakukan kepada bagian accounting CV. Muti Indofood Lestari. Hasil penelitian menunjukkan bahwa CV Muti Indofood Lestari Medan belum sepenuhnya efektif sebagai alat pengendalian biaya dikarenakan masih terdapat selisih minus antara rencana anggaran dengan realisasi anggaran biaya.

\section{KESIMPULAN}

Berdasarkan hasil penelitian dan pembahasan pada bab sebelumnya, maka dapat disimpulkan sebagai berikut:

1. Secara simultan promosi dan pelayanan berpengaruh positif terhadap tingkat kunjungan tamu pada Inna Dharma Deli Medan.

2. Secara parsial variabel promosi dan pelayanan berpengaruh terhadap tingkat kunjungan tamu, promosi dan pelayanan berpengaruh positif dan signifikan terhadap kunjungan tamu. 


\section{REFERENCES}

Cece. (2003). Analisis Hubungan Perencanaan Strategi Aliansi PDAM Tirtanadi-PT. Telekominikasi Divre I Terhadap Peningkatan Kualitas Pelayanan Pelanggan PDAM Tirtanadi... Universitas Sumatera Utara.

Dinamika, S. G., \& Siregar, E. B. A. (2016). Developing English Syllabus for Tourism Management Students. In Proceedings of the Fourth International Seminar on English Language and Teaching (ISELT-4) (Vol. 13, pp. 16-17).

Fathimah, V. (2017). Pengaruh Perkembangan Jumlah Tabungan, Deposito dan Bagi Hasil terhadap Jumlah Pembiayaan yang Diberikan oleh Perbankan Syariah di Sumatera Utara. Jurnal Ilman, 5(1), 41-52.

Hidayat, R. (2009). Penerapan Sistem lnformasi Manajemen sebagai Alat Pelaksanaan Sistem Administrasi Akademik. JURIDIKTI: Jurnal Ilmiah Pendidikan Tinggi, 2(2), 56-59.

Hidayat, R. (2010). Analisis Tingkat Penggunaan Internet Dikalangan Mahasiswa dan Hubungannya dalam Peningkatan Nilai Akademik (Studi Kasus pada Mahasiswa di Kota Medan). Jurnal Mediasi, 2(2), 55-63.

Nasution, W. A. (2009). Pengaruh kepuasan kerja karyawan terhadap intensi turnover pada call center Telkomsel di Medan. Jurnal Mandiri, 4(1), 1-11.

Nasution, W. A. (2013). Pengaruh kompensasi dan lingkungan kerja terhadap kepuasan kerja karyawan pada PT. Karya Deli Stelindo Medan. Jurnal Manajemen Bisnis STIE IBBI, 20(2), 1-77.

Nasutiona, L. K., Fahrurb, M., Christine, Imaduddind, \& Wardayani. (2017). The Calculation of Cost of Goods Sold "Gayo Arabica Coffee from Takengon" with Variable Costing Method. Journal Online Jaringan COT POLIPD (JOJAPS), 10, $82-87$.

Ningratri, Y. A. (2017). Analisis Pengaruh Strategi Bauran Pemasaran Jasa (3P) terhadap Keputusan Mahasiswa Memilih STIM Sukma Medan. Riset \& Ejurnal Manajemen Informatika, 3(1), 50-56.

Nurlinda, \& Wardayani. (2014). Pengaruh Partisipasi Penyusunan Anggaran Dan Penggunaan Instrumen Manajemen Terhadap Kinerja Pengelolaan Dana Bantuan Global Fund Komponen Aids Pada Kementerian Kesehatan Ri. Jurnal Ilman, 1(1), $23-35$.

Prana, R. R. (2016). Analisis Faktor-faktor yang Mempengaruhi Pendapatan Asli Daerah (PAD) Kota Tebing Tinggi. Jurnal Ilman, 4(1), 74-86.

Sinuhaji, E. (2010). PENERAPAN LAYANAN UNGGUL DALAM PEMASARAN PRODUK BANK. Jurnal Mediasi, 2(1).

Sukendro, H. A. (2012). Pengaruh Citra Merek dan Kualitas Pelayanan terhadap Kepuasan Jama'ah pada Kelompok Bimbingan Ibadah Haji (KBIH) Indosat Medan. Universitas Terbuka.

Supriyanto, \& Hidayat, R. (2010). Rancangan Sistem Informasi Administrasi Akademik berbasis Komputer. JURIDIKTI: Jurnal Ilmiah Pendidikan Tinggi, 3(3), 147-157.

Widjanarko, B. (2015). PENGARUH PEMERIAN KOMPENSASI DAN KOMUNIKASI TERHADAP SEMANGAT KERJA KARYAWAN PADA BUMI 
KARYA TAMA INSURANCE CABANG MEDAN. Jurnal Research Sains, 1(2), $130-152$.

Winata, E. (2015). Pengaruh Disiplin Kerja dan Budaya Kerja terhadap Semangat Kerja Karyawan pada PT. Mayasari Binangun Medan. Research Sains, 1(2), 100-117.

Winata, E. (2015). Pengaruh Pemberian Kompensasi dan Penilaian Prestasi Kerja terhadap Produktivitas kerja Karyawan pada PT. Askrindo cabang Medan. Jurnal Dunia Ilmu, 1(2).

Winata, E. (2017). ANALISA PERAMALAN PENJUALAN DAN PROMOSI PENJUALAN TERHADAP PENINGKATAN VOLUME PENJUALAN PADA PT. CAKRA ANUGERAH ARTA ALUMINDO MEDAN. Research Sains, 3(1).

Zuhri, \& Pertiwi, L. S. (2016). Airline revenue management under number of no-shows uncertainty. Global Journal of Pure and Applied Mathematics, 12(1), 1003-1012.

Zuhri. (2015). Model Input Output dan Aplikasinya pada Enam Sektor. Jurnal Ilman, $3(1), 16-21$. 